\title{
Nursing care for the elderly with hip fracture in an acute care hospital
}

\author{
Monique Weissenberger-Leduc · Michaela Zmaritz
}

Received: 14 June 2013 / Accepted: 13 October 2013 / Published online: 5 November 2013

(C) Springer-Verlag Wien 2013

Summary Elderly hip fracture patients, with and without cognitive decline, constitute an important target group for prevention. This patient group is at high-risk for in-hospital complications such as delirium, infection, pneumonia, fall, pressure ulcer and urinary tract infection. The aim of this paper is to highlight clinical pathways to meet the special care needs of older patients who have undergone treatment for a hip fracture and to ensure their rights to basic health and social care.

Keywords Hip fractures/complications/surgery · Aged/ frail elderly . Risk factors/assessment/prevention . Patient-centered care/patient care team - Patient discharge/continuity of patient care

Pflegeaspekte bei geriatrischen Patientinnen und Patienten mit Hüftfraktur im Akutkrankenhaus

Zusammenfassung Ältere Patienten mit hüftnahen Frakturen, mit oder ohne kognitiver Einschränkung, stellen eine wichtige Präventionsgruppe dar, da gerade diese Patientengruppe ein erhöhtes Risiko hat, während des stationären Aufenthalts sekundäre Komplikationen, wie zum Beispiel Delirium, Pneumonie, Sturz, Druckgeschwüre, Harnwegsinfektionen usw. zu erleiden. Ziel dieses Artikels ist es, klinische Pfade auf die speziellen Bedürfnisse alter Menschen mit Hüftfraktur hin zu

M. Zmaritz $(\bowtie)$

Vienna, Austria

e-mail: michaela.zmaritz@auva.at

Dr. Dr. M. Weissenberger-Leduc

Forum Palliative Praxis Geriatrie,

Vienna, Austria

e-mail: monique.leduc@univie.ac.at beleuchten und zu ergänzen und ihr Recht auf angemessene Gesundheits- und Sozialbetreuung herauszustellen.

Schlüsselwörter Proximale Femurfraktur/Chirurgie/ Komplikation · Alter/Frailty/Gebrechlichkeit • Risikofaktoren/Prävention - Patient-zentrierte Pflege - Case-/ Caremanagement/Entlassungsplanung

\section{Introduction}

The incidence of hip fractures is increasing in the aging population. Hip fracture is a serious and major health problem from both the individual and the public health perspective which occurs frequently. It is a common cause of a long hospital stay, is expensive, results in greater morbidity and significant disability, reduces quality of life and increases 1-year mortality [1].

The aim of this paper is to help increase the nursing safety for older people with hip fracture in acute hospital care. It should be common practice to be concerned about the safety of older patients who are admitted to the emergency department:

- What could be improved in the emergency department for patients in the acute phase of hip fracture?

- How could the health-related quality of life (HR-QOL) 1 year after the fracture be restored?

- How can we reduce:

- The high in-hospital mortality rate of $3 \%[2,3]$,

- The in-hospital acquired pressure ulcer (APU) rate of $33 \%$ [4],

- The high 6-months, 1-year and 2-years mortality rate $[3,5-7]$,

- The high readmission rate within 3 months of discharge [1], 
- The discharge rate of $58 \%$ into a nursing facility [3] and

- The substantial post-fracture decline of functional, skill and/or mental status [8]?

The only way is to minimise in-hospital complications (acute myocardial infarction, congestive heart failure, delirium, infection, pneumonia, fall, acquired pressure ulcer and urinary tract infection (UTI)) and reduce the length of hospitalisation since longer stays substantially increases a decline in the patients' health $[3,9,10]$.

\section{Patients, materials and methods}

Interventions to reduce in-hospital complications have to be correct, improved and systematically implemented in this high-risk population group. $76 \%$ of older persons with hip fracture are women (higher risk for osteoporosis), $57 \%$ live alone, $44 \%$ have pre-existing geriatric syndromes and $56 \%$ develop an acute geriatric problem (46\% major behavioural problems, $19 \%$ pressure sores and/or 5\% falls). 'All older patients with hip fracture, irrespective of their admission frailty-robustness profile, should receive geriatric evaluation and intervention' [11].

In 2012, the British Geriatrics Society (BGS) in collaboration with the British College of Emergency Medicine (CEM) published a 'Silver Book' about the 'Quality Care for Older People with Urgent and Emergency Care Needs' [12]. The US Department of Health Research and Quality also published, in March 2013, an evidence report about 'Making Health Care Safer' [13]. Both publications try to establish 'standards for safe and effective emergency care of older people' [12] and both require a holistic system approach to preserve the independence, privacy and dignity of older patients. Both publications describe an efficient, effective and safe comprehensive approach to nursing care for frail elderly patients.

The underlying principle for quality of care in terms of the patient is 'empathy', and can be viewed as a complex multi-dimensional concept of the therapeutic relationship, and involves the ability to understand the needs, meanings, fears, priorities and perspectives of elderly hip fracture patients [14]. Interaction processes between the caregiver and a patient with cognitive decline play a crucial role. They can be a source of stress, particularly if the dementia (or mild cognitive impairment (MCI)) sufferer resists the efforts of the caregiver. Clinical empathy, as a form of professional interaction and as a measure of patient-centeredness, helps:

- To increase patients' compliance, for instance by using a feed-back loop;

- To create a climate in direct care work that is free of abuse and resistiveness to care;

- To resolve hip fracture patients' problems in a therapeutic way;
- To empower the patient to cope more successfully with the new situation and to help them accept that they need assistance.

Another key factor is the nursing staff. Nurses have to increase their knowledge, understanding and ability to manage common symptoms and syndromes in older patients with hip fracture. Hip fracture patients, with and without cognitive decline, have a lot of common problems and, therefore, require intensive nursing care. According to the authors of the 'Silver Book', 'all older people that require urgent care should be routinely assessed for: pain, depression, skin integrity, falls and mobility, continence, safeguarding issues, delirium and dementia, nutrition and hydration, sensory loss, activities of daily living, vital signs and end of life care issues' all symptoms of physical, cognitive or social frailty [12].

The early identification of special needs and risks such as mortality rate, admission into nursing facilities and decline of functional skills and/or mental status should not be underestimated as shown in the statistics in the introduction. As a consequence, integrated care pathways and application of geriatric care intervention programs have to be implemented. The goal is to minimise the patients' grief, improve the treatment and reduce the burden on the healthcare system as far as conceivable throughout the pathway $[15,16]$.

Such care pathways and geriatric care intervention programs for patients with hip fracture are based on:

- 'The right care by the right team, and at the right time' [12];

- A single entry point;

- Initial physical and mental geriatric comprehensive screening and assessment;

- Geriatric multidisciplinary working and person-centred care;

- Continuity of informational, managerial and relational care;

- A supporting environment;

- A timely discharge organisation and a good transition [3].

The implementation of integrated care pathways and geriatric care intervention programs for patients with hip fracture in emergency departments (ED) is a challenge in most cases. Characteristics of an ED are e.g. noise, business, interruptions, over stimulation, and quickness of temper. These features are exactly what vulnerable elderly patients do not need, especially when they are getting into a state of crisis.

To avoid such a situation there are certain key points which the Institute of Medicine Quality Framework (IOM) describe as a valid essential way for nursing care: Timeliness, Effectiveness, Patient-centred, Efficiency and Safety [17]. 


\section{Timeliness}

Timeliness-actions resulting in unnecessary or unwanted delay [17]

'Timely [is] reducing waits and sometimes harmful delays for both those who receive and those who provide care' [17].

Hommel interviewed patients, and he showed that a lot of them assumed that they would have surgery on the same day and found waiting for surgery stressful. They seemed to lose orientation for time and place, felt very apprehensive and worried about an increased risk of infection due to the waiting time.

\section{Effectiveness}

Effectiveness-actions that align the best available evidence with optimal outcome [17].

'Effective providing services based on scientific knowledge to all who could benefit, and refraining from providing services to those not likely to benefit' [17].

For example, good pain management is a recurrently ignored aspect of hip fracture patient care and pain may contribute to a bad outcome for the patient. For example, '[c]ognitively intact patients reporting severe pain had a nine-fold higher risk of developing delirium with those whose pain was adequately treated' [18]. One of the main reasons for such poor levels of analgesia is the lack of recognition, particularly with an individual unable to speak. Pain management in older persons with cognitive decline may be challenging because of fewer skills to communicate, comorbidities and polypharmacy. Haslam describes that "[a]lthough recommendations have been published, there is currently not a standardised approach to the analgesic management of pain in the hip fracture patient' [19]. Prevalent instruments in pain management are the Verbal Rating Scale (VRS) and the Visual Analogue Scale (VAS) for patients with cognitive decline.

A multidisciplinary training program must be held in every acute hospital. All patients have a right to obtain optimal pain management. Furthermore in Hommel's study, hip fracture patients describe lots of pain problems: they felt distress from pain, tense and scared during mobilisation, abrupt mobilisation especially in the first days after surgery, and the fear of falling again. They spoke of 'intense or stabbing pain, radiating pain down towards the groin, numbness of the leg and pain in the hip' [15]. Patients perceived the pain as constant at the start of the hospital stay. Post-surgery showed the hip pain to be worse in conjunction with movement, especially when getting out of bed, as a consequence they laid still to avoid pain. Patients did not like going to the bathroom because of the unsuitable sitting position. They spoke about 'an ordeal' [15]. This can be an obstacle in toilet training and leads to further complications and delays in restitution. Nursing staff should therefore make sure that the toilet booster seat is adapted for hip fracture patients.

Patients also think it is difficult to become mobile and walk again. They would prefer more training with a physiotherapist before being discharged. Good collaboration and communication between surgeon, nurse and physiotherapist is essential for achieving good pain relief in advance, particularly when mobilisation takes place one day after surgery [15].

\section{Patient-centered}

'Patient-centered: providing care that is respectful of and responsive to individual patient preferences, needs, and values, and ensuring that patients' values guide all clinical decisions' (...) 'Emphasizes care coordination, continuity, communication, education, and shared decision-making' [17].

Especially the pre-operative period can be very hard on patients. They describe a 'feeling of hunger and thirst, and having a dry mouth' while waiting for surgery. This is a needless suffering for frail elderly patients and fasting is a modifiable risk for malnutrition. Good mouth-care, as often as necessary, is a quick and secure way to reduce these feelings. Nurses should know and use the procedures for oral intake before surgery.

Training tips, ideas and suggestions to achieve the best restitution results and to get well again have to be adapted not only with respect to the resources and impairments of the patient in the hospital but also for the patient's future requirements.

Verbal information about the hip, the surgery and training of the leg needs to be tailored to the special needs of the individual patient using geriatric screening. The nurse has to ensure that the information has been understood well by the patient, that all questions have been answered, to minimise, for example, the anxiety about going home. Weekly information sessions about hip fractures were implemented at the Department of Orthopaedics, Lund University Hospital, Sweden, in 2007. Patients who took part in the session found it profitable [15].

\section{Efficiency}

'Efficiency: actions which cause no overuse or underuse of resources, e.g. investigation, treatment, etc. avoiding waste, including that of equipment, supplies, ideas and energy' [17]

A well-managed admission of older people with hip fracture to hospital which is based on clinical assessment can prevent adverse effects. Adverse effects are associated with higher care cost and burden for patients and caregivers. Preventive interventions e.g. for delirium, infec- 
tion, pneumonia, fall, acquired pressure ulcer (APU), urinary tract infection (UTI) are available. Many nursing staff implemented evidence-based bundles which the Institute for Healthcare Improvement defined as a set of evidence-based practices. Generally three to five such practices showed that, when performed collectively and reliably, patient outcomes improve [20].

\section{Methicillin-resistant Staphylococcus aureus bundle}

For instance hospitals implemented an evidence-based MRSA (methicillin-resistant Staphylococcus aureus) bundle, including four evidence-based practices: active surveillance, hand hygiene, patient isolation and the use of personal protective equipment such as gowns and gloves [13].

\section{Bladder bundle}

The Bladder bundle against UTI and incontinence includes four evidence-based practices:

- Intervention to avoid unnecessary urinary catheter (UC) placement using institutional guidelines, physician and nursing staff training regarding UC use.

- Appropriate indications for UC insertion, list of inappropriate reasons to insert was provided and an UC indication checklist was attached to UC kits.

- Intervention for prompt removal of unnecessary catheters with stop order:

- Daily checklist for evaluating UCs;

- Urinary retention protocol by the nurse;

- Request for removal;

- Daily use of a checklist in the multidisciplinary meeting to determine if an UC was still indicated;

- Sticker applied to medical records to remind physicians to discontinue unnecessary UCs;

- Renew UC order $72 \mathrm{~h}$ after placement.

- Nurses were empowered to assess UC need by protocol and to remove UCs no longer needed [21].

\section{Preventing in-facility falls bundle}

Vulnerable patients have many factors associated with increased risk of falls and fractures during admission. Advanced age, comorbidity, malnutrition, anaemia, mobility and cognitive impairment, confusional syndrome development during admission, polypharmacy, admission from a nursing home and a high demand for nursing care are such common factors [22].

Preventing in-facility falls is considered a quality-ofcare indicator:
- Due to the association with a $30 \%$ increase in mortality and a fourfold increase in hospital stay [23];

- Because patients who fell during hospitalisation, especially on more than one occasion, are at high risk of falling again at home after hospital discharge and may not be able to live independently at home [1, 3, 24-26].

An underlying principle for preventing in-facility falls requires close cooperation between orthopedic surgeons, nurses, physiotherapists (PT), occupational therapists (OT), dietician and geriatricians involved in intervention. The goals are to minimise falls, the related negative outcomes and to improve the quality of patient care.

A description of measures for an anti-fall program is outlined below:

- A fall assessment tool has to be implemented in a fall prevention program. The aim is to screen all patients upon admission, at least every $24 \mathrm{~h}$, and after certain trigger events to detect patients at high risk of falling and suggest interventions of care;

- Specific risk factors such as activity, altered mobility, cognitive decline, unsteady gait, disorientation, toilet problems, medication issues, need standard fall prevention measures as an additional tailored team intervention and safe environment;

- All significant risk patients received visual identification such as stickers, wrist bands, door signs, and low beds with internal alarms. Doors were kept open, curtains pulled back, hip protectors and orthostatic hypotension assessment were done. Side rails should only be raised when the patient feels more secure otherwise it is a restraint;

- Environmental modification recommendations to reduce environmental hazards were proposed such as a reclining chair, quiet zones in the hallways.

- Daily uses of a checklist in multidisciplinary meetings to discuss a total care plan for each patient on the unit have to be implemented;

- New patient educational materials were developed; patients and relatives were informed about the measures;

- A crucial aspect of success is to change the attitude of nurses: from low to high prioritisation of falls and from disinterest to pride and enthusiasm [27].

\section{Preventing in-facility delirium and frailty bundle: the 'ABCDE bundle'}

It is very important to distinguish between dementia, delirium and depression, but it should not be forgotten that many elderly hip fracture patients, with and without cognitive impairment, are often unable to provide an accurate history about themselves. A history of the patient's pre-admission state should be sought from a relative, caregiver or general practitioner. Increasing evidence shows that a lot of elderly hip fracture patients are at risk for developing common, dangerous and poten- 
tially iatrogenic conditions such as delirium and frailty in an intensive care unit (ICU). ICU-acquired delirium and frailty are related:

- To facility problems resulting in higher ICU and hospital costs;

- To longer ICU admissions and overall hospital length of stay (LOS);

- To greater use of continuous sedation and physical restraints;

- To increased self-removal of catheters and self-extubation;

- To higher ICU mortality and reduced quality of life;

- To post-discharge sequelae such as a greater likelihood of being discharged into a nursing facility;

- To significant long-term physical, functional, and cognitive decline;

- To a higher 6-month and 1-year mortality rate;

- To durable neurocognitive impairment. Patient with delirium are three times higher at risk of developing dementia later in life [12].

In 2012, Balas proposed a multidisciplinary bundled method to prevent ICU-acquired delirium and frailty: The Awakening and Breathing Coordination, Delirium Monitoring and Management, and Early Mobility (ABCDE) bundle. It includes delirium, immobility, sedation/analgesia and ventilator management, fits pharmacologic and non-pharmacologic interventions for every day clinical practices in the ICU [20].

The ABCDE bundle primarily includes evidencebased practices such as:

- Improving communication by measure of a daily used checklist in multidisciplinary meetings to discuss the total care plan for each patient on the unit;

- Standardising care processes;

- Breaking the cycle of over-sedation and prolonged mechanical ventilation because the prevalence of delirium in mechanically ventilated adults is as high as $83 \%$

- Training nurses to use screening instruments, empower them to recognise and to treat underlying causes and to help them to promote an environment with a reality orientation patient-centeredness approach $[12,20]$

- Nurses play a unique role in the implementation of ABCDE. They are crucial to all requirements for a successful implementation and they are the communication link between each of the individual specialties [20].

It is essential that clinicians and nurses routinely use valid and reliable delirium screening tools since evidence shows that preventing delirium is more effective than treating it-once it has arose. Inouye developed the Confusion Assessment Measure (CAM) and the CAMICU on the basis of Diagnostic and Statistical Manual of Mental Disorders, Fourth Edition (DSM-IV) criteria [28].
The CAM is the extensively used tool and a German version has been published and validated [29].

The syndrome delirium is often not recognised, and therefore poorly managed. It is frequently 'invisible' for caregivers, but not for patients. The patients told Hommel that they had hallucinations at night which then disappeared in the morning. 'Several patients also described seeing 'silent old men' everywhere, on the curtain and on the chairs in the room. They tried to speak to the old man, but got no response... in the night I saw shadows, it was like no faces, and they stood around me, they were figures, nobody made a sound, no faces that I can remember, it was very strange ... another patient said:... then I thought a man was standing there/.../he was so close that I thrust out my hand/.../and my hand just vanished out in empty space/.../so I was hallucinating' [15]. The staff did not recognise delirium in connection with such descriptions and explained that this was not unusual.

According to the ABCDE bundle, every admitted patient to an adult ICU should undergo a routine sedation or agitation and delirium assessment by using standardised, validated delirium screening instruments (CAM-ICU) to identify risk factors for developing delirium. (Vanderbilt University http://www.icudelirium.org) Measurements should be carried out once per shift whenever a patient experiences a change in their mental status, and at least during the daily interdisciplinary meeting to diagnose precipitating factors for delirium. Interdisciplinary meetings should help to review all medication at least every $24 \mathrm{~h}$. The actual cause of the syndrome can only be treated when it is recognised. The interdisciplinary care team includes at least a physical therapist, a respiratory therapist, surgeon (confirms that there are no clinical contraindications to physical activity), physician, dietician and nurses.

In 2013, the American Psychiatric Association published the Diagnostic and Statistical manual of mental disorders DSM- $5^{\mathrm{TM}}$. A description of the new diagnostic criteria is outlined below:

(a) A disturbance in attention (i.e., reduced ability to direct, focus, sustain, and shift attention) and awareness (reduced orientation to the environment).

(b) The disturbance develops over a short period of time (usually hours to a few days), represents a change from baseline attention and awareness, and tends to fluctuate in severity during the course of a day.

(c) An additional disturbance in cognition (e.g., memory deficit, disorientation, language, visuospatial ability, or perception).

(d) The disturbances in Criteria A and C are not better explained by another preexisting, established, or evolving neurocognitive disorder and do not occur in the context of a severely reduced level of arousal, such as coma.

(e) There is evidence from the history, physical examination, or laboratory findings that the disturbance is a direct physiological consequence of another medical condition, substance intoxication or withdrawal (i.e., 
Table 1 Risk factors for delirium

\begin{tabular}{|l}
\hline Predisposing factors \\
\hline Older age ( $\geq 70$ years) \\
\hline Severe illness and/or multimorbidity \\
\hline Neurocognitive disorders: dementia, depression and/or disorientation \\
\hline Functional impairment: physical frailty or immobility and/or falls \\
\hline Admission with infection and/or pain \\
\hline Polypharmacy, drugs and/or alcohol abuse \\
\hline Poor nutrition and/or dehydration \\
\hline Constipation and/or urine catheters \\
\hline Poor vision or hearing problems \\
\hline History of delirium or stroke \\
\hline Precipitating factors \\
\hline $\begin{array}{l}\text { Biochemical derangements or/and infection (systemic inflammatory } \\
\text { response) }\end{array}$ \\
\hline Severe intercurrent illness, surgery, trauma or/and urgent admission \\
\hline Use of physical restraint, use of bladder catheter \\
\hline Any iatrogenic events \\
\hline Electrolyte or metabolic disorders, fasting \\
\hline $\begin{array}{l}\text { Adverse effects of anticholinergic or dopaminergic drugs or/and sedation } \\
\text { with medication }\end{array}$ \\
High noise level, poor light, sleep disturbance or privation [12, 31-33] \\
\hline
\end{tabular}

due to a drug of abuse or to a medication), or exposure to a toxin, or is due to multiple etiologies [30].

Tables 1 and 2 provide information for identifying risk and precipitating factors for delirium and how nurses can recognise them.

Other management issues such as prevention of pressure sores, incontinence or malnutrition are very wellknown and nurses are usually very well-trained to handle those problems. If a vulnerable elder is admitted to the hospital, the assessment of pressure ulcer, cognitive, functional and nutritional status as a part of the geriatric assessment should be done within $24 \mathrm{~h}$. The authors will, therefore, not address these issues in the article as this would exceed the scope of the paper.

Some evidence-based practices underpin nearly every bundle to meet the care needs of older hip fracture patients, with and without cognitive decline, and are summarised below:

- The recommended multidimensional holistic approach from admission to discharge in the ED can meet patients' expectations and ensure their right of remaining autonomous as well as receiving appropriate, equal and fair treatment with dignity and respect;

- People are admitted to ED with a multitude of nursing care needs from minor injuries and illness through to life threatening conditions;

- They have to be seen as patients with common geriatric problems and a high risk for in hospital adverse effects:

- They have psychological, social and emotional needs that often require highly skilled nursing care;
Table 2 Assessments and management of suspected delirium

\begin{tabular}{|c|c|}
\hline \multicolumn{2}{|c|}{ Recognise delirium: Assessment } \\
\hline \multirow[t]{4}{*}{ History } & Perform at admission a baseline cognitive function test \\
\hline & $\begin{array}{l}\text { Check recent changes in the patient's mental status: ask } \\
\text { the family, the GP, home care staff }\end{array}$ \\
\hline & Check changes in disorder, new diagnoses, and new drugs \\
\hline & $\begin{array}{l}\text { Check alcohol and/or drugs use (including over-the-counter } \\
\text { drugs) }\end{array}$ \\
\hline Vital signs & Measure and notice vital signs \\
\hline $\begin{array}{l}\text { Physical } \\
\text { examination }\end{array}$ & $\begin{array}{l}\text { Search for signs of infection, pain, dehydration } \\
\text { Assess for sensory vision and/or hearing impairments }\end{array}$ \\
\hline \multirow[t]{6}{*}{$\begin{array}{l}\text { Cognitive } \\
\text { examination }\end{array}$} & $\begin{array}{l}\text { Notice sudden changes in the patient's condition like being } \\
\text { more confused or more disorganised than usual }\end{array}$ \\
\hline & $\begin{array}{l}\text { Notice confusion fluctuation during the day and increasing } \\
\text { at night }\end{array}$ \\
\hline & $\begin{array}{l}\text { Notice memory problems, disorientation, hallucinations, } \\
\text { delusions and change in sleeping patterns }\end{array}$ \\
\hline & $\begin{array}{l}\text { Notice a rambling or jumping from one topic to another if } \\
\text { the patient is easily distracted. }\end{array}$ \\
\hline & $\begin{array}{l}\text { Notice activity-levels if the patient appears more agitated } \\
\text { or more sleepy than usual. }\end{array}$ \\
\hline & $\begin{array}{l}\text { Identify changes in manner of conversation if the patient } \\
\text { has difficulty to focus attention. }[16,31-33]\end{array}$ \\
\hline \multicolumn{2}{|c|}{ Prevention of delirium and its complications: Management } \\
\hline \multicolumn{2}{|c|}{ Use non-drug measures first } \\
\hline \multirow[t]{5}{*}{$\begin{array}{l}\text { Reorientation } \\
\text { strategies }\end{array}$} & $\begin{array}{l}\text { Encourage family to maintain supportive relationships } \\
\text { Basale Stimulation }{ }^{\odot} \text {, Validation }{ }^{\odot} \text {, music, reduce disorienta- } \\
\text { tion by avoiding inter- and/or intra-ward transfers avoid } \\
\text { physical or drug restraints; remove all lines/catheters as } \\
\text { soon as possible }\end{array}$ \\
\hline & $\begin{array}{l}\text { Take note that this does not prevent falls and may increase } \\
\text { the risk of injury }\end{array}$ \\
\hline & $\begin{array}{l}\text { Reduce disorientation by having clocks, calendars and } \\
\text { orientation }\end{array}$ \\
\hline & $\begin{array}{l}\text { Boards in each room and encourage frequent re-orientation } \\
\text { by staff }\end{array}$ \\
\hline & $\begin{array}{l}\text { Ensure hearing aids, glasses, and teeth are used, in order, } \\
\text { and accompany patients when being transferred }\end{array}$ \\
\hline \multirow{5}{*}{$\begin{array}{l}\text { Identify } \\
\text { psychosocial } \\
\text { triggers }\end{array}$} & Remain calm and do not get angry (it never helps) \\
\hline & Avoid direct confrontation and provocation \\
\hline & $\begin{array}{l}\text { Find out what is worrying the patient and what they want } \\
\text { to be done about it: anxiety about getting home, strange } \\
\text { noises, snoring, Offer to help }\end{array}$ \\
\hline & $\begin{array}{l}\text { Reassure the patient that he or she is not going to be } \\
\text { harmed }\end{array}$ \\
\hline & Focus on empathising with the distress (through) \\
\hline \multirow{2}{*}{$\begin{array}{l}\text { Iden- } \\
\text { tify physical } \\
\text { causes }\end{array}$} & $\begin{array}{l}\text { Search for signs of pain, thirst, need for the toilet, cath- } \\
\text { eters, sleep disturbance }\end{array}$ \\
\hline & $\begin{array}{l}\text { Obtain a nutrition/dietary consultation } \\
\text { Reduce the risk of problems caused by medication } \\
{[12,31-33]}\end{array}$ \\
\hline
\end{tabular}

- Therefore, these patients need comprehensive geriatric care intervention programs with screening instruments and assessments to evaluate the individual risk factors upon admission; 
- A state-of-the-art, effective, central, holistic approach for the patient includes an adaptation of the environment to reduce iatrogenic risk factors and an efficient planning of the discharge process to prevent geriatric syndromes;

- A supporting environment reduces disorientation and gives a feeling of security;

- The interdisciplinary team needs very good communication links between each of the individual specialists (multidisciplinary teams);

- Multi-dimensional concepts of professional interaction with standardised care processes allows prompt diagnosis of the common problems of the elderly patient and allows intervention for the implementation of evidence-based burden management;

- Education programs must include the patients' family and caregiver and shared decision-making improves compliance [12, 13].

- Discharge planning within this framework begins with admission to the hospital [8].

\section{Safety}

'Safety: actions that cause no unnecessary harm, avoiding injuries to patients from the care that is intended to help them' (...) 'These questions will be asked for each transition and will address the quality of the handover information received, the quality of the interchange, and their perception of whether the transition could have been avoided and, if they believe that it could have been prevented, what could have prevented the transition' [17].

One way to avoid injury is to implement routine screening and to ask patients (and if necessary, the family) about sensory deficiencies [33]. Grue described that only $16 \%$ of patients with hip fracture had no sensory impairments, $15.4 \%$ had vision, $38.6 \%$ hearing and $30 \%$ had combined sensory impairments. Among the impaired, $81 \%$ were female, $80 \%$ were living alone, $48 \%$ had secondary diagnoses of cognitive impairments, $51 \%$ of bladder incontinence, $27 \%$ underweight, comorbidity and polypharmacy, $90 \%$ had impaired Activities of Daily Living (ADLs), 71 \% in Instrumental Activities in Daily Living (IADLs) [33]. The nursing staff need to organise environmental adjustments and create a feeling of security for patients with sensory impairments. Such help could be in the way of:

- Battery checks for hearing and acoustic aids; magnifying glasses;

- Telephones, radios and buzzer with large buttons;

- A big clock in front of the bed;

- Daylight as far as possible; well-lit corridors as well as notice sensibility to light;

- Providing name tags and notice boards with big letters.
These environmental adjustments will also help with orientation for time and place. A lot of sensory deficiencies can be treated or minimised with technology that improves the ability to live independently at home.

\section{Discharge planning}

Discharge planning begins with admission to hospital. This is very important for good discharge planning and for the post-dromal phase of hip fracture. Older patients with hip fracture should only be discharged when

- The patient's and their caregiver's situation, perspective and feelings have been identified. Patients are sometimes very concerned about the need for assistance. For instance who will have time to help them with activities such as showering when they return home? This makes them feel insecure and uneasy;

- Their discharge preferences have been understood, communicated and checked for accuracy;

- An adequate support for on-going and future care after discharge is ensured;

- Efficient and timely information has been shared between hospital and healthcare providers;

- Well-functioning communication exists when transferring the patient from one point to another in the healthcare system;

- Evidence-based care components on the prevention of subsequent fractures such as information about osteoporosis, education and empowerment of the patient and their caregivers has been delivered; the use of hip protectors reduces hip fracture rates of up to $60 \%$ [18].

- Information about access for financial support has been elucidated and if required application forms have been filled out.

Case management discharge planning and good transition has to be in place after discharge. Follow-up homevisits by case managers and PT have to be organised for at home patients and patients have to have easy access to their general physicians (GP).

\section{Discussion}

The authors tried to point out that the outcome of older patients with hip fracture is closely linked with a holistic therapeutic approach. The broad spectrum of publication shows the demand for prevention work such as assessment instruments, adapted environment and professional caring for a quick and sufficient recovery.

A translation of evidence based strategies into everyday care has to be carried out to decline the rate of adverse effects. Frontline user engagement is crucial for the successful implementation and sustainability of evidence-based bundles and tools. 
It is also necessary to acknowledge the difference of the roles in this prevention work without underestimating any of the parties. Nursing staff is highly involved in this complex assignment because of their close proximity in time and place to the patients. Adequate nurse staffing and well-educated nurses are crucial points to aim at the goal of optimal care and prevention of harm. Brief but periodically in-service training of nurses has to be implemented and should base on relevant age related changes and evidence-informed strategies.

The perceived main barrier to sustain implementation is the high workload on surgical units [2]. From the economically view of every institution or health care provider, labour costs play the most predominant role. The tendency to focus on lowering labour costs by reducing staff-especially in nursing-has to be reconsidered. A general framework for a modern patient-centred health care system is needed. Patient's safety is at stake in times of declining financial budgets and simultaneously increasing patient numbers in addition to a higher need of care because of a longer lifespan.

Further research has to be implemented to ensure that new assessment instruments and methods match the problems of elderly patients.

\section{Conflict of interest}

The authors declare that there is no actual or potential conflict of interest in relation to this article.

\section{References}

1. Gregersen M, Morch MM, et al. Geriatric intervention in elderly patients with hip fracture in an orthopedic ward. J Inj Violence Res. 2012;4(2):45-51.

2. Schubert M, Clarke SP, et al. Associations between rationing of nursing care and inpatient mortality in Swiss hospitals. Int J Qual Health Care. 2012;24(3):230-8.

3. Bentler SE, Liu L, et al. The aftermath of hip fracture: discharge placement, functional status change, and mortality. Am J Epidemiol. 2009;170(10):1290-9.

4. Baumgarten M, Margolis D, et al. Use of pressure-redistributing support surfaces among elderly hip fracture patients across the continuum of care: adherence to pressure ulcer prevention guidelines. Gerontologist. 2010;50(2):253-62.

5. Juliebo V, Krogseth M, et al. Medical treatment predicts mortality after hip fracture. J Gerontol A Biol Sci Med Sci. 2010;65(4):442-9.

6. Schnell S, Friedman SM, et al. The 1-year mortality of patients treated in a hip fracture program for elders. Geriatr Orthop Surg Rehabil. 2010;1(1):6-14.

7. Panula J, Pihlajamaki H, et al. Mortality and cause of death in hip fracture patients aged 65 or older: a populationbased study. BMC Musculoskelet Disord. 2011;12:105.

8. Arora VM, Fish M, et al. Relationship between quality of care of hospitalized vulnerable elders and postdischarge mortality. J Am Geriatr Soc. 2010;58(9):1642-8.

9. Baumgarten M, Margolis DJ, Orwig DL, et al. Pressure ulcers in elderly patients with hip fracture across the continuum of care. J Am Geriatr Soc. 2009;57(5):863-70.

10. Hagino H, Nakamura T, Fujiwara S, et al. Sequential change in quality of life for patients with incident clinical fractures: a prospective study. Osteoporos Int. 2009;20(5):695-702.
11. De Brauwer I, Lepage S, Yombi JC, et al. Prediction of risk of in-hospital geriatric complications in older patients with hip fracture. Aging Clin Exp Res. 2012;24(1):62-7.

12. Agency for Healthcare Research and Quality (AHRQ). Quality care for older people with urgent \& emergency care needs: 'Silver Book'. GB; 2012.

13. AHRQ Evidence Report/Technology Assessment Number 211. Making Health Care Safer II: An Updated Critical Analysis of the Evidence for Patient Safety Practices. Rockville: U.S. Department of Health and Human Services, MD 20850; 2013.

14. Mercer SW, Reynolds WJ. Empathy and quality of care. Br J Gen Pract 2002;52(Suppl):9-12.

15. Hommel A, Kock ML, Persson J, et al. The patient's view of nursing care after hip fracture. ISRN Nurs; 2012

16. Gonzalez Montalvo GJI, Alarcon Alarcon T, Pallardo Rodil $\mathrm{B}$, et al. Acute orthogeriatric care (II). Clinical aspects. Rev Esp Geriatr Gerontol 2008;43(5):316-29.

17. The Institute of Medicine Quality Framework (IOM)/Committee on Quality of Health Care in America. crossing the quality chasm: a new health system for the 21 st century. Washington D.C.; 2001.

18. Colon-Emeric CS, Saag KG. Osteoporotic fractures in older adults. Best Pract Res Clin Rheumatol 2006;20(4):695-706.

19. Haslam L, Lansdown A, Lee J, et al. Survey of current practices: peripheral nerve block utilization by ed physicians for treatment of pain in the hip fracture patient population. Can Geriatr J 2013;16(1):16-21.

20. Balas MC, Vasilevskis EE, Burke WJ, et al. Critical care nurses' role in implementing the "ABCDE bundle" into practice. Crit Care Nurse 2012;32(2):35-8, 40-7.

21. Fakih MG, Watson SR, Greene MT, et al. Reducing inappropriate urinary catheter use: a statewide effort. Arch Intern Med. 2012;172(3):255-60.

22. Zapatero A, Barba R, et al. Hip fracture in hospitalized medical patients. BMC Musculoskelet Disord 2013;14:15.

23. Brand CA, Sundararajan VA 10-year cohort study of the burden and risk of in-hospital falls and fractures using routinely collected hospital data. Qual Saf Health Care 2010;19(6):e51.

24. Hustey FM. Care transitions between nursing homes and emergency departments: a failure to communicate. Ann Long-Term Care: Clin Care Aging 2010;18(4):17-9.

25. Gillespie SM, Gleason LJ, Karuza J, Shah MN. Health care providers' opinions on communication between nursing homes and emergency departments. J Am Med Dir Assoc 2010;11(3):204-10.

26. Davenport RD, Vaidean GD, Jones CB, et al. Falls following discharge after an in-hospital fall. BMC Geriatr 2009;9:53.

27. Weinberg J, Proske D, Szerszen A, et al. An inpatient fall prevention initiative in a tertiary care hospital. Jt Comm J Qual Patient Saf. 2011;37(7):317-25.

28. Inouye SK. Delirium in older persons. $\mathrm{N}$ Engl J Med 2006;354(11):1157-65.

29. Guenther U, Popp J, Koecher L, et al. Validity and reliability of the CAM-ICU. Flowsheet to diagnose delirium in surgical ICU patients. J Crit Care 2010;25(1):144-51.

30. American Psychiatric Association. "Diagnostic and Statistical Manual of Mental Disorders, DSM-5 ${ }^{\mathrm{TM}}$; 5 th edn. Arlington: American Psychiatric Association; 2013.

31. Siddiqi N. Preventing delirium in older people. Nurs Times 2011;107(21):22-3.

32. Inouye SK. Delirium in elderly people. Lancet. 2013 Aug 27:1-12.

33. Grue EV, Kirkevold M, Ranhoff AH, et al. Prevalence of vision, hearing, and combined vision and hearing impairments in patients with hip fractures. J Clin Nurs 2009;18(21):3037-49. 